J. Venom. Anim. Toxins incl. Trop. Dis.

V.13, n.2, p.428-429, 2007.

Editor's viewpoint.

ISSN 1678-9199.

\title{
The Journal of Venomous Animals and Toxins including Tropical Diseases (JVATiTD) from 1995 to 2007
}

Scientific journals are undoubtedly the greatest tools for Toxinology worldwide. Unfortunately, no more than ten units are currently distributed for the five continents.

In 1995, a group of researchers from The Center for the Study of Venoms and Venomous Animals launched a periodical on this subject. Since 2003, the editorial board of The Journal of Venomous Animals and Toxins decided to adopt a politics for the growth and internationalization of the journal. The first step was to change its title to The Journal of Venomous Animals and Toxins including Tropical Diseases, aimed at increasing its subject area. Then, a process to increase the frequency of publication from twice a year to three times a year and then four times a year was developed. This initiative was based on the minimum goals suggested by the international scientific community for journals of the biological area, which consists in publishing at least four numbers and 32 scientific articles per year.

In addition, endogeny, i.e. the publication of at least $70 \%$ papers from the journal's institution, has to be gradually reduced to promote internationalization. Thus, in 2003, we published two numbers containing 16 scientific articles: six (37.5\%) from our institution (UNESP), three (18.75\%) from other Brazilian research institutions, and seven (43.75\%) from different countries (Saudi Arabia, India, the United Kingdom and Egypt).

In 2004, we published three numbers totalizing 22 papers. Out of these, 11 (50\%) were from UNESP, six (27.27\%) from other Brazilian research institutions, and five (22.72\%) from different countries (Venezuela, Egypt, Colombia and India). In 2005, we achieved the desired four numbers per year containing 44 scientific articles. Out of these, 26 (59.09\%) were from UNESP, ten (22.72\%) from other Brazilian research institutions, and eight (18.18\%) from different countries (Saudi Arabia, India, Bulgaria, Turkey and Mexico).

In 2006, we consolidated the four numbers per year and, again, published 44 papers: 15 (34.09\%) from UNESP, five (11.36\%) from other Brazilian research institutions, and 24 (54.54\%) from different countries (India, Argentina, Iran, Egypt, Australia, Saudi Arabia, Turkey, Korea, Uruguay, Japan and Sudan). Now, we are encouraging international researchers to submit their papers in order to increase the participation of the international community in our periodical. We also intend to obtain important indexations, which will improve the publication spreading and consolidation. It must be emphasized that the contribution from São Paulo State University (UNESP), the virtual library SciELO (Scientific Electronic Library Online), The National Council for Scientific and Technological Development (CNPq) and The Coordination for the Improvement of Higher Education Personnel (CAPES) has been extremely important for the support and maintenance of the journal.

The Figure below shows JVATiTD's performance: 


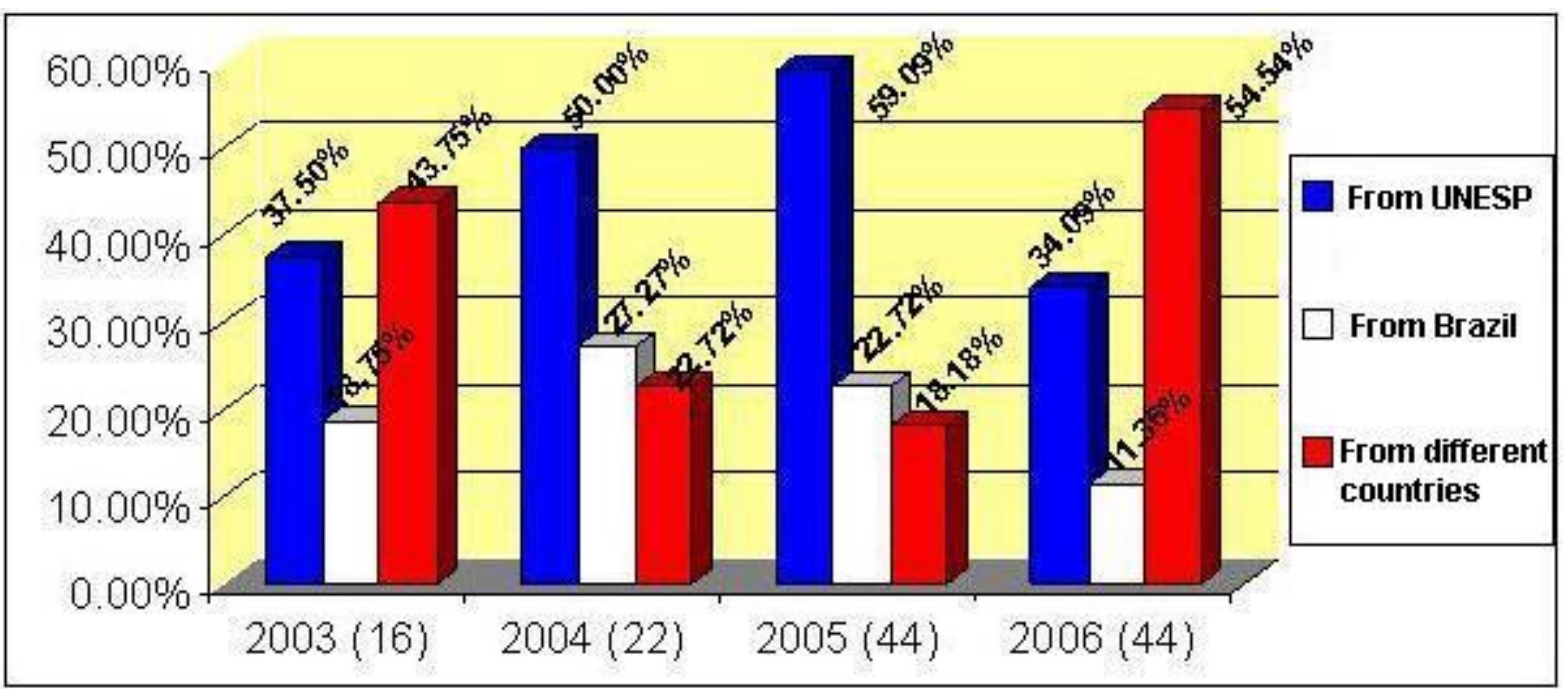

Figure 1: Frequency of papers published in The Journal of Venomous Animals and Toxins including Tropical Diseases from 2003 to 2006.

\section{CORRESPONDENCE TO:}

BENEDITO BARRAVIERA, Caixa Postal, 576, 18.618-000, Botucatu, SP, Brasil. Email: bbviera@jvat.org.br. 